\title{
Experimental Study of Wind Booster Addition for Savonius Vertical Wind Turbine of Two Blades Variations Using Low Wind Speed
}

\author{
Eflita Yohana ${ }^{1, *}$, MSK. Tony Suryo U ${ }^{1}$, Binawan Luhung ${ }^{2}$, Mohamad Julian Reza ${ }^{2}$, and M Badruz Zaman ${ }^{1}$ \\ ${ }^{1}$ Department of Mechanical Engineering, Faculty of Engineering, Diponegoro University, Semarang - Indonesia \\ ${ }^{2}$ Bachelor of Mechanical Engineering, Faculty of Engineering, Diponegoro University, Semarang - Indonesia
}

\begin{abstract}
The Wind turbine is a tool used in Wind Energy Conversion System (WECS). The wind turbine produces electricity by converting wind energy into kinetic energy and spinning to produce electricity. Vertical Axis Wind Turbine (VAWT) is designed to produce electricity from winds at low speeds. Vertical wind turbines have 2 types, they are wind turbine Savonius and Darrieus. This research is to know the effect of addition wind booster to Savonius vertical wind turbine with the variation 2 blades and 3 blades. Calculation the power generated by wind turbine using energy analysis method using the concept of the first law of thermodynamics. The result obtained is the highest value of blade power in Savonius wind turbine without wind booster $(16.5 \pm 1.9) \mathrm{W}$ at wind speed $7 \mathrm{~m} / \mathrm{s}$ with a tip speed ratio of $1.00 \pm 0.01$. While wind turbine Savonius with wind booster has the highest power $(26.3 \pm 1.6) \mathrm{W}$ when the wind speed of $7 \mathrm{~m} / \mathrm{s}$ with a tip speed ratio of $1.26 \pm 0.01$. The average value of vertical wind turbine power increases Savonius after wind booster use of $56 \%$.
\end{abstract}

Keywords: Savonius; Wind Booster; Power; Tip Speed Ratio.

\section{Introduction}

The more advanced a nation, the greater the electricity needs of the people. Power plants supply this electricity demand, where the majority of energy sources of power plants still use fossil energy. While the availability of fossil energy is getting limited and the negative impact on the environment is quite much. The use of fossil fuels produces greenhouse gases [1]. These gases absorb heat energy that the earth will emit into space, causing a warming of the troposphere.

Efforts to reduce global warming continue to be carried out. Various countries have made innovations, ranging from making regulations to limit the use of energy that has an impact on global warming to the use of renewable energy to reduce global warming. Renewable energy is an energy that can be renewed and can be used continuously. Its sources are obtained from the sun, wind, gas, and others. It provides many advantages such as can be found anywhere and basically has a small effect on the environment. One of them is wind energy, it is clean energy and in the production process, it does not pollute the environment [2].

The use of renewable energy is still limited, this is due to a lack of research. While the use of it can be an investment in the future. Wind power has been used for 3000 years. Until the 20th century. At the beginning of modern industrial world, the use of wind energy sources is replaced by fossil fuel engines or electricity networks [3].

Wind turbines are a tool used in the Wind Energy Conversion System (SKEA). Wind turbines can produce electricity by converting wind energy into kinetic energy through a blade contained in the turbine and rotating the shaft on the generator to produce electricity [4]. The turbine is divided into two types, Horizontal Axis Wind Turbines (HAWT) and Vertical Axis Wind Turbines (VAWT). Horizontal Axis Wind Turbine (HAWT) is designed to produce electricity from wind at high speed. Vertical Axis Wind Turbine (VAWT) is designed to produce electricity from wind at low speeds. [5].

One of the turbines classified as VAWT is the Savonius wind turbine. This wind turbine has a simple construction that operates independently of the wind direction and starts at low wind speeds that were developed and patented by Sigurd J. Savonius in the $1920 \mathrm{~s}$. The best rotor has an efficiency of $31 \%$ while the efficiency of the prototype is $37 \%$ [6].

Based on data from BMKG, in Indonesia, especially in the city of Semarang, the average wind speed is around $2.5 \mathrm{~m} / \mathrm{s}$ [7]. Even though wind speeds are low, Indonesia has wind potential that is available almost throughout the year. This makes it possible to develop a small-scale wind power plant system.

The purpose of this study was to analyze the value of the power obtained based on the speed of the incoming wind that pushed the turbine blade and the value of wind

\footnotetext{
* Corresponding author: efnan2003@gmail.com
} 
speed out of the turbine, analyze the value of the wind turbine shaft rotation resulting from variations in wind speed, the difference in the number of turbine blades, and the addition of wind booster. Then analyze the comparison of the power values resulting from variations in wind speed differences. The difference in the number of turbine blades and the addition of wind booster.

\section{Research Method}

\subsection{Tool Scheme}

Fig. 1 and Fig. 2 explain the scheme of wind turbine testing tools using wind booster and without using wind booster.

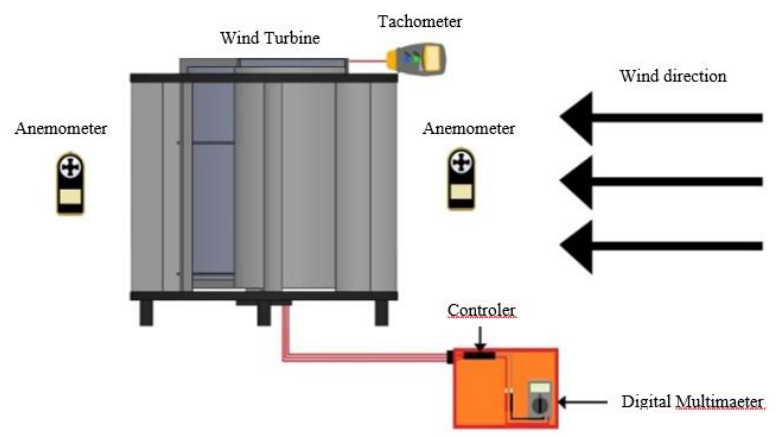

Fig. 1. Scheme of wind turbine testing tools using wind booster

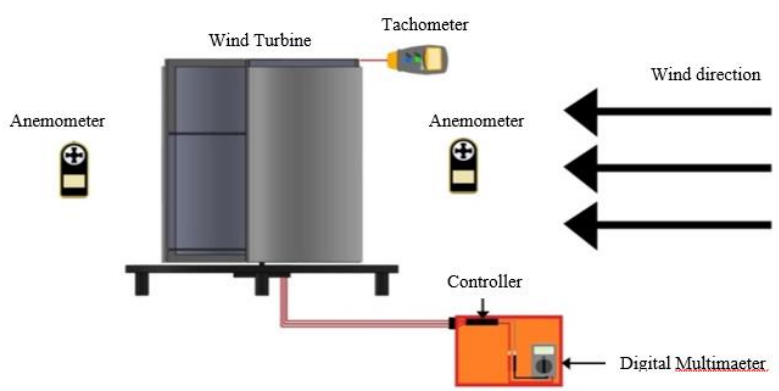

Fig. 2. Scheme of wind turbine testing tools without using wind booster

\subsection{Flow Chart}

The flow chart used in the research process can be seen in Fig. 3.

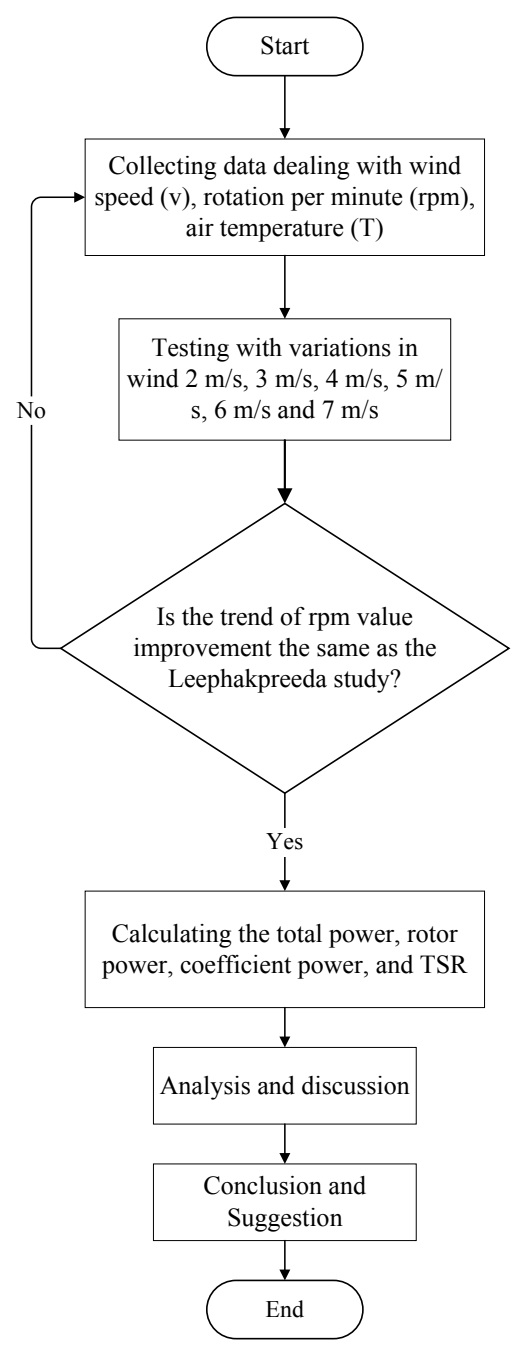

Fig. 3. Research flow chart

\subsection{Wind Power Analysis}

Wind power is energy that can be produced by the wind at a certain speed that hits a wind turbine in a certain area. The wind power produced by the one that hits the wind turbine can be known through equation 1 [8].

$$
P_{t o t}=\frac{1}{2 g_{c}} \rho A V_{i}^{3}
$$

where $g_{c}$ is a conversion factor with a value of $1.0 \mathrm{~kg} /$ $\left(\mathrm{N} . \mathrm{s}^{2}\right), \rho$ is the density of air, A is the cross-sectional area, and $V_{i}$ is the speed of the wind entering the wind turbine. The values of $\rho$ and $\mathrm{A}$ are known from equations 1 and 2 . While the value of $V_{i}$ is known by using an anemometer.

$$
\rho=\frac{P}{R T}
$$

where $\mathrm{P}$ is the environmental pressure with a value of 1 atm, $R$ is a specific gas constant with a value of $287.05 \mathrm{~J} /$ kg.K, and $\mathrm{T}$ is the ambient temperature with a value of $305 \mathrm{~K}$.

$$
A=H D
$$

where $\mathrm{H}$ is the blade height of 0.65 meters and $\mathrm{D}$ is the blade diameter of 0.57 meters.

\subsection{Blade Power Analysis}


Blade power is the power extracted by the blade from the wind. Blade power can be known through equation 4 [8].

$$
P_{\text {tot }}=\frac{1}{4 g_{c}} \rho A\left(V_{i}+V_{e}\right)\left(V_{i}^{2}-V_{e}^{2}\right)
$$

where $V_{e}$ is the speed of the wind coming out of the turbine. The $V_{e}$ value is measured using an anemometer.

\subsection{Coefficient Power (Cp) Analysis}

The power coefficient $(\mathrm{Cp})$ is the ratio between the power produced by the wind. The $\mathrm{Cp}$ value is known through equation 5 [8].

$$
C p=\frac{\text { Power out }}{\text { Powet in }}=\frac{P}{P_{\text {tot }}}
$$

Ideally, the coefficient power is the maximum power ratio obtained from the wind with total wind power, or $C p_{\max }=0.59$. The value of $C p_{\max }$ is obtained from Betz's theory.

\subsection{Tip Speed Ratio Analysis}

Tip speed ratio (TSR) is the ratio of wind speed to blade rotational speed in wind turbines [9]. The TSR value is known through equation 6 [8].

$$
T S R=\frac{\omega D}{2 V_{i}}
$$

where $\omega$ is the blade angle speed $(\mathrm{rad} / \mathrm{s})$. The value $\omega=\frac{2 \pi N}{60}, \mathrm{~N}$ is the blade rotational speed (rpm).

\subsection{Validation}

The research journal used for this validation is a research journal conducted by Natapol Korprasertsak and Thananchai Leephakpreeda in 2016 [10]. In this study, the researcher was looking for the influence of wind speed on rotational speed as Fig. 4.

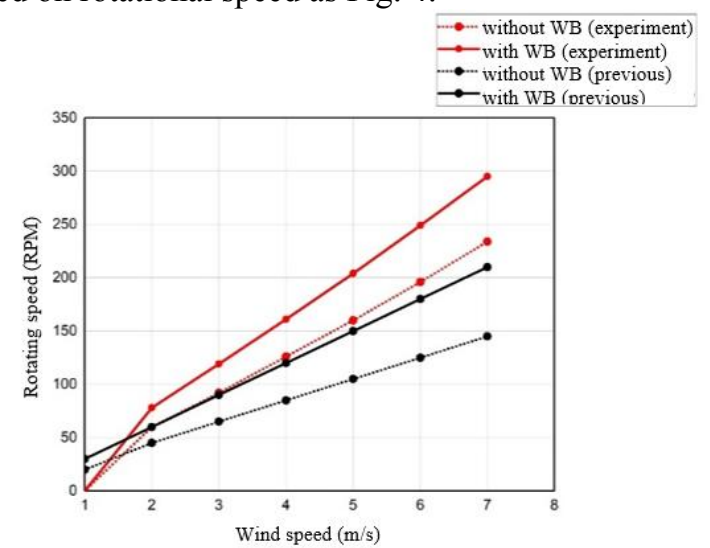

Fig. 4. Validation of the wind speed effect on RPM

Fig. 4 described that the rotational speed has an increase in wind speed. This is because wind speed will affect how fast the blade rotates. The greater the wind speed, the faster the blade rotation. The black line of the graph illustrates the magnitude of the rpm value in the previous study, while the red line describes the magnitude of the rpm value in this study. Black and red graphs have a tendency to both increase.

\section{Analysis and Discussion}

The value of the blade power has increased along with the increase in wind speed as in Fig. 5. This is because the blade power is strongly influenced by the speed of the wind in and the speed of the wind comes out. The greater the difference in the speed of the incoming wind and the speed of the wind coming out, the greater the wind extracted by the turbine. This graph is in accordance with the results of research conducted by Nur Alom and Ujjwal K. Saha [11].

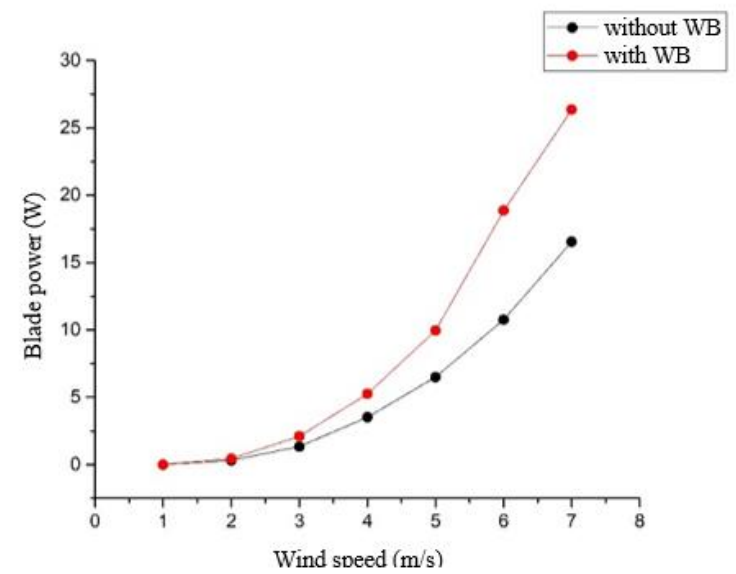

Fig. 5. The graph of a relation between wind speed and blade power

TSR value increases with increasing wind speed as shown in Figure 6. This is due to the important factor in TSR calculation which is the ratio of blade rotational speed to wind speed. The greater the ratio of rotational speed with wind speed, the higher the speed ratio tip. This graph is in accordance with the results of research conducted by Frederikus Wenehenubun, Andy Saputra and Hadi Sutanto [12].

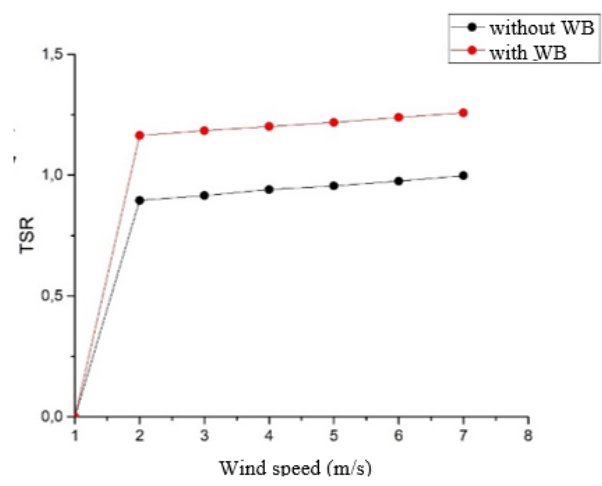

Fig. 6. The graph of a relation between wind speed and Tip Speed ratio

Fig. 7 shows the results of a study conducted by W. ElAskary, et al. [13] 


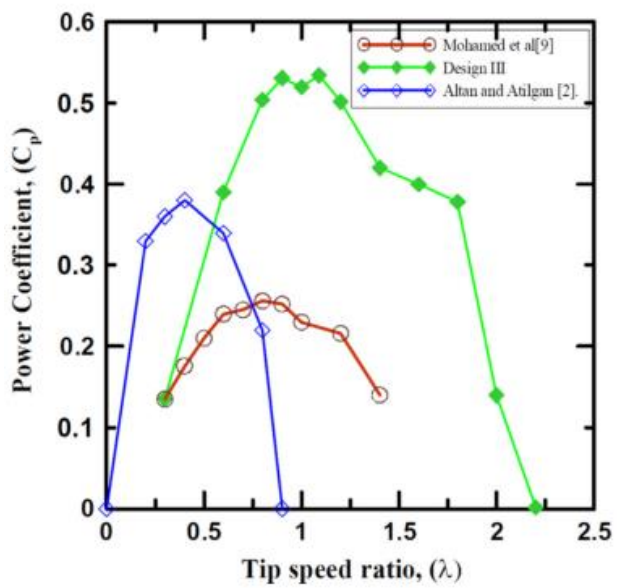

Fig. 7. The graph of TSR and Cp blade two blades from reference [13]

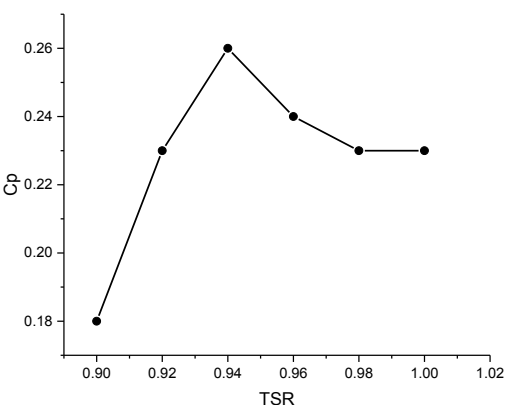

(a)

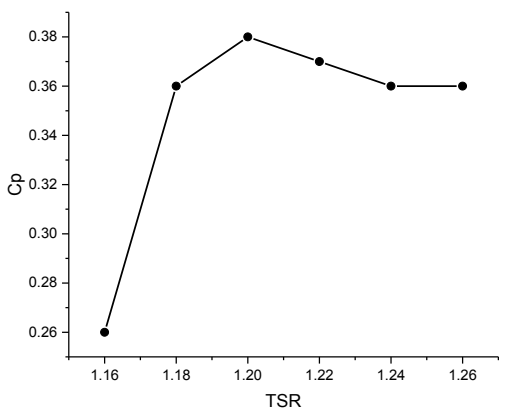

(b)

Fig. 8. The graph of TSR and Cp blade two blades (a) without wind booster and (b) with wind booster

From Fig. 8, it is known that the biggest power coefficient value for two blades without wind booster is 0.26 with a TSR of 0.94 . While for two blades with wind booster is 0.38 with TSR 1.2. Using formula (5), it is known that the power coefficient value is affected by wind power and blade power. If the value of the ratio of wind power and blade power is greater, the power coefficient value is large.

\section{Conclusion}

The test results obtained are the highest blade power values produced from two blades wind turbines with a wind booster of 26.37 watts with a wind speed of $7 \mathrm{~m} / \mathrm{s}$. TSR value of the highest wind speed in wind turbines using wind booster is 1.26 at a wind speed of $7 \mathrm{~m} / \mathrm{s}$. The power coefficient value produced by two blades wind turbine without a wind booster is shown in Figure 7 (a) of 0.26 at a TSR value of 0.94 . The power coefficient value produced by each variable has different values, in two blades wind turbine with a wind booster, the highest power coefficient value is 0.38 at a TSR value of 1.20.

\section{References}

1. I. Smith, Carbon Dioxide and Climatic Change, Energy Explor. Exploit. 6(6), 465-475 (1988)

2. M. Nakajima, S. Iio, T. Ikeda, Performance of Savonius Rotor for Environmentally Friendly Hydraulic Turbine, J. Fluid Sci. Technol. 3(3), 420429 (2008)

3. V. Nelson, Wind Energy: Renewable Energy and the Environment, CRC Press (2009)

4. J.K. Kaldellis, M. Kapsali, K.A. Kavadias, Energy Balance Analysis of Wind-Based Pumped Hydro Storage Systems in Remote Island Electrical Networks, Appl. Energy 87(8), 2427-2437 (2010)

5. M.M.M. Saad, N. Asmuin, Comparison of Horizontal Axis Wind Turbines and Vertical Axis Wind Turbines, IOSR J. Eng. www.iosrjen.org ISSN 04(08), 2250-3021 (2014)

6. S.J. Savonius, The S-rotor and its applications, Mechanical 53(5) (1931)

7. BMKG, Semarang City Weather Forecast, Online.. Available: http://www.bmkg.go.id/cuaca/prakiraancuaca/. Accessed: 19-Dec-2017

8. M. M. El-Wakil, Powerplant Technology. McGrawHill (1985)

9. J.F. Manwell, J.G. McGowan, A.L. Rogers, Wind Energy Explained: Theory, Design, and Application (2009)

10. N. Korprasertsak, T. Leephakpreeda, Analysis and Optimal Design of Wind Boosters for Vertical Axis Wind Turbines at Low Wind Speed, J. Wind Eng. Ind. Aerodyn. 159, 9-18 (2016)

11. N. Alom, U.K. Saha, Four Decades of Research into the Augmentation Techniques of Savonius Wind Turbine Rotor, J. Energy Resour. Technol. Trans. ASME 140(5), 1-14 (2018)

12. F. Wenehenubun, A. Saputra, H. Sutanto, An Experimental Study on the Performance of Savonius Wind Turbines Related with the Number of Blades, Energy Procedia 68, 297-304 (2015)

13. W.A. El-Askary, M.H. Nasef, A.A. AbdEL-hamid, H.E. Gad, Harvesting Wind Energy for Improving Performance of Savonius Rotor, J. Wind Eng. Ind. Aerodyn. 139, 8-15 (2015) 